Military Facilities Engineering Technology

\title{
Towards a Pre-Intervention Analytical Methodology
}

Lucy A. Whalley, Timothy K. Perkins, David A. Krooks, August 2012

Michael L. Hargrave, and Chris C. Rewerts 



\section{Towards a Pre-Intervention Analytical Methodology}

Lucy A. Whalley, Timothy K. Perkins, David A. Krooks, Michael L. Hargrave, and Chris C. Rewerts

Construction Engineering Research Laboratory

U.S. Army Engineer Research and Development Center 2902 Newmark Drive

Champaign, IL 61822

Final report

Approved for public release; distribution is unlimited.

Prepared for U.S. Army Corps of Engineers

Washington, DC 20314-1000

Under Project P2 335530, “Cultural Reasoning and Ethnographic Analysis for the Tactical Environment (CREATE)” 


\section{Abstract}

Few systematic methods are available to guide analysis of sociocultural dynamics for the planning of civil-military operations (CMO). Military practice provides limited guidance on how to address history and sociocultural context in planning. Each case is addressed as a unique situation, at a high cost in terms of time and effort. This text, first presented to the " 2 nd International Conference on Cross-Cultural Decision Making: Focus 2012," describes emerging results of a project entitled "Cultural Reasoning and Ethnographic Analysis for the Tactical Environment (CREATE)." A primary objective of the CREATE research is to develop a sociocultural analytical methodology to guide the sensemaking of analysts who support CMO planning.

The methodology centers on a formal analytical framework that organizes a wide variety of sociocultural factors that, according to the social science literature, directly and indirectly pertain to a specific problem space. Data sources, analytical methods, and tools are aligned with the framework to produce guidance on how to develop models of a particular situation. The focus of the framework is to provide insight from social science research into the drivers of instability in the partner nation to aid analysts in developing explanations for situations of interest to a combatant command.

DISCLAIMER: The contents of this report are not to be used for advertising, publication, or promotional purposes. Citation of trade names does not constitute an official endorsement or approval of the use of such commercial products. All product names and trademarks cited are the property of their respective owners. The findings of this report are not to be construed as an official Department of the Army position unless so designated by other authorized documents. 


\section{Table of Contents}

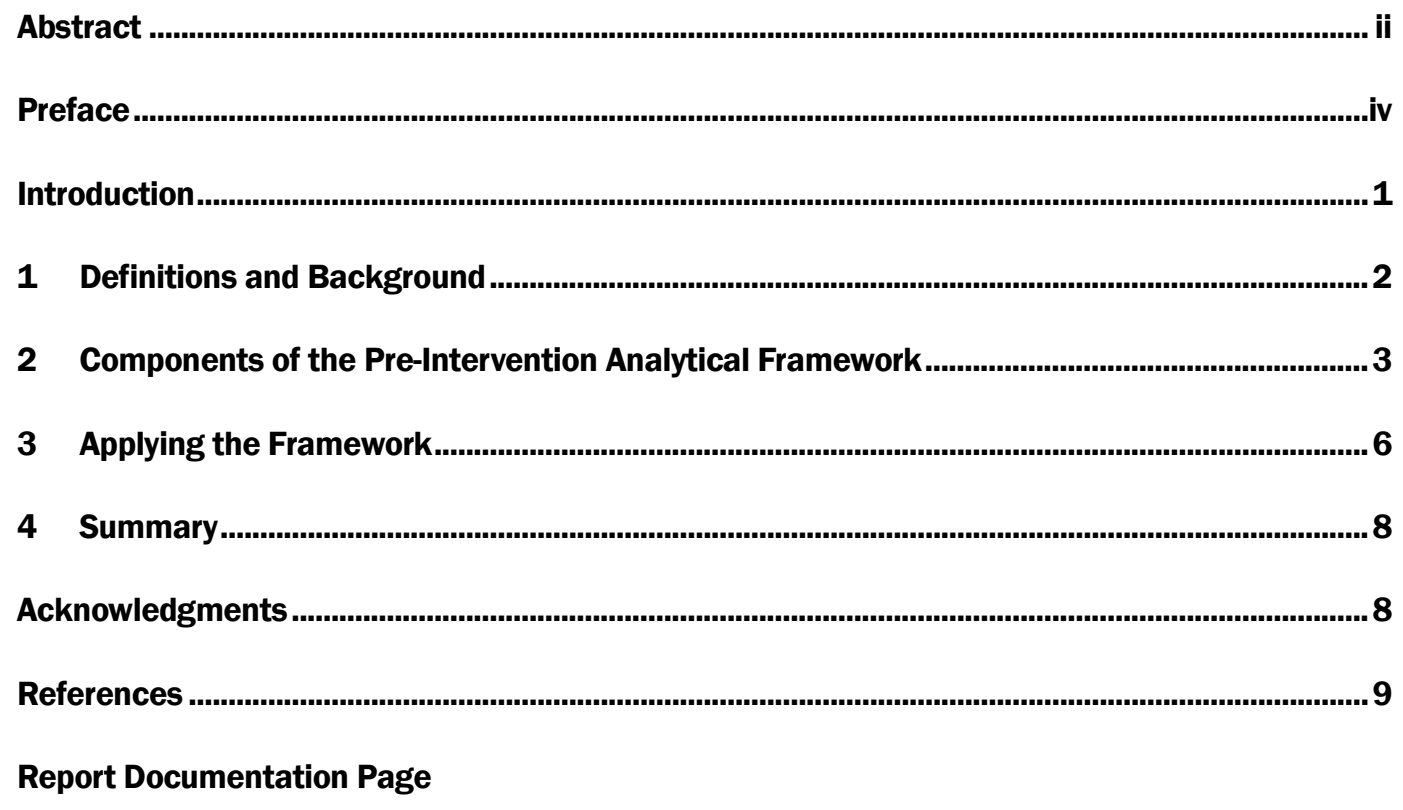




\section{Preface}

This study was conducted for the Headquarters, US Army Corps of Engineers, under Research, Development, Test, and Evaluation (RDTE) Program Element 622784 T41, "Military Facilities Engineering Technology"; Project P2 335530, "Cultural Reasoning and Ethnographic Analysis for the Tactical Environment (CREATE)." This text was originally presented as a paper at the "2nd International Conference on Cross-Cultural Decision Making: Focus 2012,"J uly 2012, San Francisco, CA.

The work was performed by the Land and Heritage Conservation Branch (CN-C) of the Installations Division (CF), US Army Engineer Research and Development Center - Construction Engineering Research Laboratory (ERDC-CERL). At the time of publication, Dr. Christopher M. White was Chief, CEERD-CN-C; Michelle J . Hanson was Chief, CEERD-CN; and Dr. Alan B. Anderson was the Technical Director for Military Ranges and Lands. The Deputy Director of ERDC-CERL was Dr. Kirankumar Topudurti and the Director was Dr. Ilker Adiguzel.

COL Kevin J. Wilson was the Commander and Executive Director of ERDC, and Dr. J effery P. Holland was the Director. 


\title{
Towards a Pre-Intervention Analytical Methodology
}

\author{
Lucy A. Whalley; Timothy K. Perkins; David A. Krooks; \\ Michael L. Hargrave; Chris C. Rewerts
}

\section{INTRODUCTION}

The civil-military community has few systematic methods to guide analysis of sociocultural dynamics for the planning of civil-military operations (CMO). Military practice has often viewed histories and local sociocultural contexts as eminently unique, while providing limited guidance about how to include these factors in planning. Thus, each situation is addressed individually and at high cost in terms of time and labor, since history and local sociocultural context are treated as if they were disconnected or insurmountably complex factors. This paper describes the emerging results of a research and development project of the US Army Corps of Engineers, Engineer Research and Development Center entitled "Cultural Reasoning and Ethnographic Analysis for the Tactical Environment (CREATE)." A primary objective of the CREATE research is to develop a sociocultural analytical methodology to guide the sensemaking of analysts who support CMO planning. The methodology is centered on a formal analytical framework that organizes a constellation of relevant sociocultural factors, which, according to the social science literature, directly and indirectly pertain to a particular problem space. Aligned with the framework will be data sources, analytical methods, and tools that provide guidance on how to work from the framework to develop models of a particular situation.

The focus of the pre-intervention analytical framework is to identify and represent the sociocultural dynamics relevant to understanding the situation on the ground for scenarios of instability in which CMO might be conducted with a partner nation. In this context, the goal of CMO is to enhance the capacity of the partnernation government to diminish the ability of those who oppose it to maneuver among the population.

This paper describes the development of the pre-intervention analytical framework and how an analyst may apply it to support CMO planning. 


\section{DEFINITIONS AND BACKGROUND}

CMO are defined by US Department of Defense doctrine as:

The activities of a commander that establish, maintain, influence, or exploit relations between military forces, governmental and nongovernmental civilian organizations and authorities, and the civilian populace in a friendly, neutral, or hostile operational area in order to facilitate military operations, to consolidate and achieve operational US objectives. CMO may include performance by military forces of activities and functions normally the responsibility of the local, regional, or national government. These activities may occur prior to, during, or subsequent to other military actions. They may also occur, if directed, in the absence of other military operations. CMO may be performed by designated civil affairs, by other military forces, or by a combination of civil affairs and other forces. (Joint Publication [JP] 1-02, 52).

Analysts supporting CMO must strive to provide "timely, accurate, usable, complete, relevant, objective, and available" (JP 2-01, 2012) information about the operational environment. This situation on the ground must be understood as objectively as possible, not in terms of what we personally believe it ought to be, or what our experience tells us that it might be.

\subsection{What is a frame?}

Framing is a process that is associated with the literature on sensemaking, including the work of Klein Associates for the US Army Research Institute for the Behavioral and Social Sciences (Sieck et al. 2007), which compares the use of frames by novice and experienced analysts. The concept of frame has been used in the behavioral and social sciences for decades. For example, Piaget $(1952 ; 1954)$, who contributed fundamental concepts to social psychology, conceives of a frame as a schema that is a mental representation of the persistent features and attributes of objects, which enables learning. Goffman (1974), whose thinking is fundamental to sociology, sees a frame as a culturally relative system of rules that organizes society and guides individual behavior. In addition, the concept of framing or working from a framework has been integrated into such applied methodologies as the Millennium Ecosystem Assessment Framework; the workshops of Elinor Ostrom at Indiana University, Bloomington; and the Counterterrorism Analytical Framework (JP 3-26, 2009). A framework serves to orient and guide analysis of a particular situation, whereas a model is situated to the specific place and problem and is contextualized with data for a specific situation. The framework is not designed to generate the model but suggests, instead, what an analyst may need to consider for developing a model.

Sieck et al. (2007:117) demonstrate how frames are used to form explanations of a particular situation. Experts rely on various frames that are "fragments of local cause-effect connections, rules of thumb, patterns of cues, and other linkages and 
relationships between cues and information to guide the sensemaking process" (Sieck et al. 2007:vi). We have organized a number of frames into a single framework that is oriented to address a particular problem area. That framework is designed to enable the development of insights from social science research and to support model building for understanding the sociocultural dynamics of a particular situation.

\subsection{Requirements of the CREATE Analytical Framework}

The pre-intervention analytical framework is intended to serve as a tool for rapidly orienting and guiding an analysis of a situation that becomes an area of interest for CMO. Since the locations of CMO change, analysts may not necessarily be experts on new societies of interest. In addition, timely identification and engagement of the right experts are often challenges during the period available for conducting analysis. The aim of the framework is to:

(1) Focus analysis on those aspects of a situation of interest that will enable the rapid formulation of plausible explanations,

(2) Guide the identification of data that can be used to address the types of questions associated with explaining a particular situation,

(3) Identify the knowledge gaps that can be filled only by the collection of data on the ground.

The framework must be applicable from the national to the local level and generalizable across locales and civil-military engagement scenarios. The framework should focus on factors and relationships relevant to understanding scenarios in which civil-military operators will engage at the invitation of a partner nation. The analyst will enter the picture during the pre-intervention assessment phase and be challenged to make sense of a scenario so that planners can scope and design the nature of their engagement.

\section{COMPONENTS OF THE PRE-INTERVENTION ANALYTICAL FRAMEWORK}

\subsection{Developing the Foundation for the Framework}

The grounding of the initial concept of the framework in social science is described in an internal draft report (Zhang et al. 2011). This foundational framework builds upon the approach of Elinor Ostrom's Institutional Analysis and Development Framework (Ostrom 2011). As illustrated in Figure 1, use of the framework begins with an observed or anticipated instability, resulting in a decision to begin

planning CMO. The second step requires an understanding of the contexts within which actors interact. This identifies the inputs of the actors, the rules-in-use, and 
the resources as they interact within opportunity structures in particular contexts. Our concept of opportunity structure is based on Kitschelt's (1986:58) description of political opportunity structure, which is "comprised of specific configurations of resources, institutional arrangements and historical precedents for social mobilization, which facilitate the development of protest movements in some instances and constrain them in others." In addition, Kitschelt (1986:59) depicts political opportunity structures functioning "as 'filters' between the mobilization of the movements and its choice of strategies and its capacity to change the social environment." Thus, in our application, the concept of opportunity structure serves to include the interaction among actors, rules-in-use, and resources.

Actors in the form of persons or groups both shape and are shaped by the rules active in their environment. Further, these actors may disagree about or compete for the use of particular resources, whether physical or intangible. The framework guides the analysis of causation or interdependencies. Determination of feedbacks between human motives and structural factors helps to identify which specific sociocultural theories apply to a given situation. Ultimately, an examination of context creates an analysis of the characteristics of the instability and the resulting vulnerabilities and resiliencies. Here, vulnerabilities are understood as characteristics of the social system that can weaken a population and its ability to respond to stress. Resiliencies are characteristics that determine how a population reacts and can withstand or adapt to stress (Cutter et al. 2010).

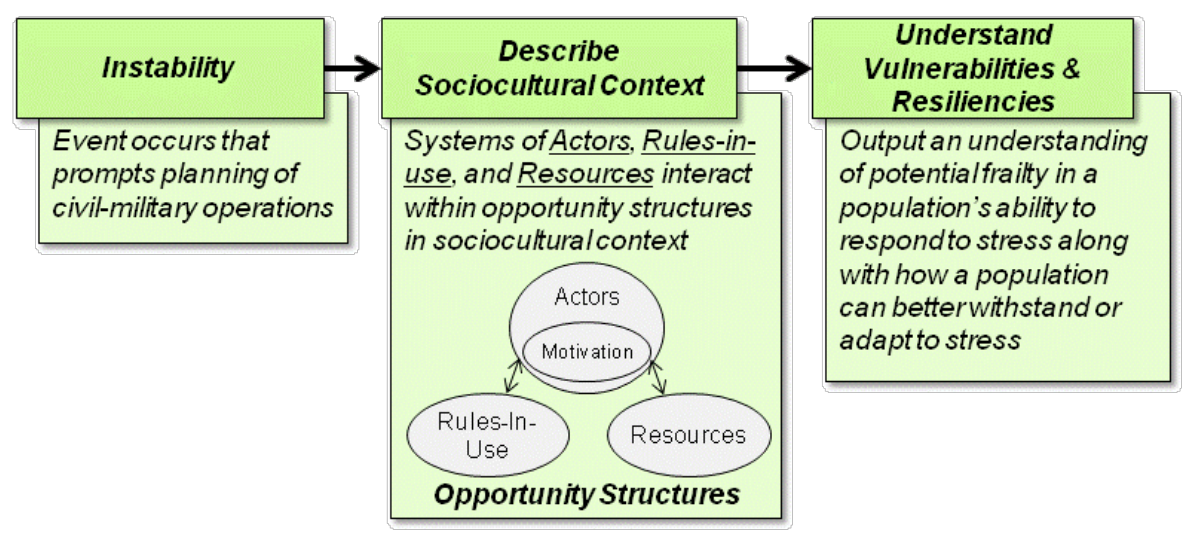

Figure 1. Foundation of the Pre-Intervention Analytical Framework

Application of the foundational framework yields a 'systems view' of the operational environment.

\subsection{Operationalizing the Foundational Framework}

More detail is necessary in order to enable analysts supporting CMO to work from the framework towards understanding and modeling a particular situation. Thus, the next phase of the work on the framework is developing sufficiently de- 
tailed representations to enable an analyst to apply the framework for understanding the production and maintenance of insurgency.

There is considerable debate in the academic and military literature on defining insurgency vis-à-vis terrorism (Rich and Duyvesteyn 2012; US Army Counterinsurgency Center, December 2011). Rather than resolve that debate at this point, we focused our literature search for the analytical framework as follows:

- Insurgency is expressed by persistent conflict directed against a national government, i.e. a recognized administrative body of the state;

- These conflicts are between governments of state(s) and non-state actors;

- Non-state actors who profess a global insurgency will direct their efforts against states, which embody all that they are against ideologically, and/or will attempt to insinuate themselves in localized insurgencies.

A goal for operationalizing the framework is to create a representation of academic and military-focused literature that explains the production and maintenance of insurgency. The literature grounding the framework must be characterized and made accessible so that an analyst can gain access to knowledge that has been collected and trace arguments back to original documents. Currently, only social science literature is represented in the framework. Ongoing research will incorporate unclassified material on insurgency developed by and for the US Department of Defense. The following is a brief description of the approach used to develop the operationalizable framework; additional details will be published in a forthcoming Technical Report.

Concept mapping was used to develop the first iteration of a factor map that would aid a formal, structured search for relevant literature. The foundational framework represents social actors as exercising influence and power as they interact within social systems employing rules-in-use and resources. Guided by the foundational framework, the team identified potential factors that contribute to the production and maintenance of insurgency. Thus far, analysis of the social science literature suggests that nine factors are critical: power relations, ideology, grievance, recruitment, physical space, economic strength, and strength of government institutions. These factors form the core of the factor map that is discussed below.

The team is now engaged in a further review of the social science literature in order to confirm, dismiss, or add factors related to the production and maintenance of insurgency. To assess the relevant literature, the team has both conducted a broad sweep and consulted social scientists from a variety of disciplines. The broad sweep entailed identifying keywords associated with factors, applying the keywords to Google Scholar, assessing returns, and refining keywords used to conduct the search. Abstracts flagged by Google Scholar were collected and evaluated for linkages between the factors and insurgency. The articles were also downloaded, resulting in a corpus of approximately 400 peer-reviewed articles. Linkages of factors to insurgency were identified by the phrases 'gives rise to,' 'results in,' 'is required by,' or 'contributes to.' Factors were sorted by how the literature said they contributed to the production and maintenance of insurgency and then visually mapped into 
groups that contribute directly or indirectly to the production and maintenance of insurgency. The broad-sweep search resulted in further iterations of the factor map.

The team is evaluating the extent of coverage by the broad sweep of theories associating factors with insurgency. Working documentation of the process for creating the factor map includes the rationale for the placement of factors in the map, definitions of factors, the references to the literature upon which these decisions are based, and the range of arguments presented in the literature associating the factors with insurgency. The goal is to provide traceable paths from the documents to factors and linkages in the factor map. The digital corpus of the articles and sections of books cited will be part of the delivery of the operationalized framework.

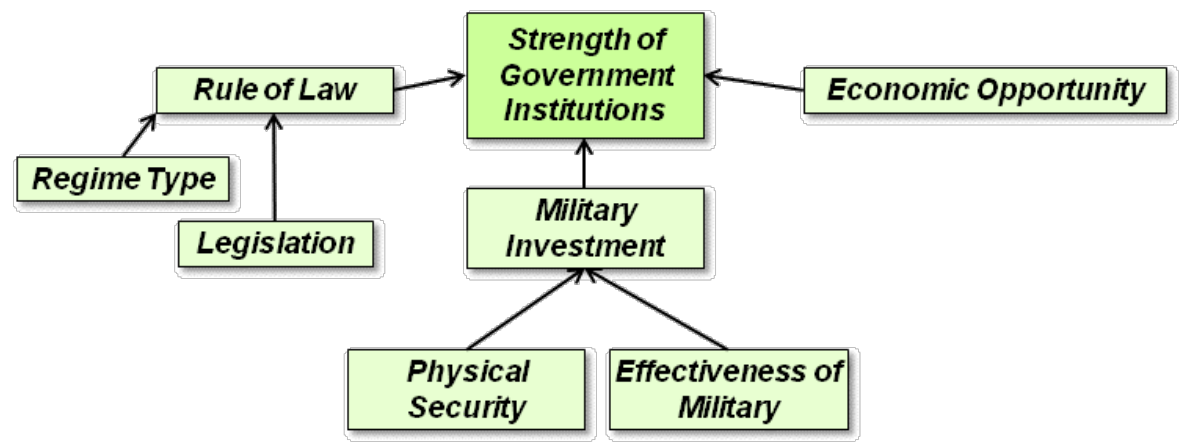

Figure 2. Example draft factor diagram.

Figure 2 shows a subset of the factor map and focuses on strength of government institutions and those other factors that the literature shows to be related.

\section{APPLYING THE FRAMEWORK}

\subsection{Need and Capability}

According to doctrine and discussions with stakeholders, analysts are expected to analyze and understand the operational environment from holistic, systems, and geospatial perspectives. They must also account for the military's experience that irregular warfare and "stability operations require an approach that places far greater emphasis on understanding the civil population..." and may "require JIPOE analysts to adopt a nontraditional, broad view of what constitutes an 'adversary"' (JP 201.3, IV-1-2). Development of these holistic and systems perspectives is frequently too time consuming, and "commanders and their staffs are often overwhelmed with details and can quickly reach information overload" (JP 2-01.3, IV-12).

The framework will provide a thoroughly documented starting point for analysis of sociocultural factors. Understanding of an operational environment is developed when an analyst selects those frames from the framework that assist in characterizing a particular situation. The analyst can then apply situationally relevant data in 
order to develop an explanatory model (i.e., conceptual and/or computational) of the situation. This enables comparatively quick review, understanding, and integration of new information.

Also contributing to this capability is the use of tools, such as concept maps (Kaste 2007), mind maps, and dynamically interactive networks, available from a variety of proprietary, government, and open sources. Using these tools, systemic representations may be developed, and evidence can be tied to nodes and links. For analysts supporting $\mathrm{CMO}$, the emerging framework will enable visual, transparent, and traceable access to critical academic and military literature that examines the sociocultural factors that contribute to insurgency and violent extremist organizations. The remainder of this section provides a brief example of the use of the analytical framework.

\subsection{Example Application}

A civil-military operational context (e.g., humanitarian assistance or small-scale support projects in a semi-hostile area) requires swift but deliberate involvement of host-nation and international partners. Prior to deploying significant resources, a Joint Intelligence Preparation of the Operational Environment (JIPOE) assessment is to be prepared. As part of the JIPOE, an analyst receives a validated request for information (e.g., on the degree of influence of a violent extremist organization within the host-nation and the capacity of the host-nation government to diminish that influence). First, the analyst deconstructs the request for information with reference to the particular situation in which operations will be conducted. For this example, an analyst will want to know which violent extremist organizations are known to be operating in the area of interest and what the broader context of their involvement is. Enabling this characterization of the situation on the ground is the raison d'être for this analytical framework.

The framework leads the analyst to identify social actors, resources, and rulesin-use interacting within opportunity structures as a means of characterizing the situation. In our hypothetical example, the social actors are the violent extremist organization, the host-nation government, any groups opposing the host-nation government, and any other groups that support or are neutral with respect to the hostnation government. If an opposition group can be defined as an insurgency, then our analytical framework provides guidance on how to understand its production and maintenance. Figure 2 presents an example of a small component of the larger factor map that captures the analytical framework graphically. The component chosen for presentation in Figure 2 is strength of government institutions, which is influenced by the subfactors rule of law, military investment, and economic opportunity. Analysis of the literature assembled to develop the framework reveals how social science research relates each factor to the production and maintenance of insurgency. For example, the strength of government institutions is related to the perception of their legitimacy by the citizenry (Manwaring et al. 1992). A government can gain wider support from the citizenry by controlling extra-legal violence (i.e., military investment in Figure 2) and minimizing public corruption (i.e., rule of law in Figure 
2). For a particular situation that involves a violent extremist organization and an insurgency, an analyst would investigate how the perception of government legitimacy either increases or decreases support for the agendas of the violent extremist organization and the insurgents.

The analyst then reviews whether the data available for the particular operational environment confirms or questions the explanations provided via use of the framework. The framework serves as inspiration (or 'frames,' in the language of the sensemaking literature) for a characterization and analysis of the operational environment. Accessing intelligence and open-source information, the analyst prepares documents, relates them to a situated explanatory model, and transmits the resulting products. When the analytical framework is fully developed and implemented with software, multiple analysts will be able to provide input and updates to an explanatory model, which represents a traceable conceptual model of situationally relevant sociocultural knowledge.

\section{SUMMARY}

This paper has sketched the development of a sociocultural analytical framework that can be used to expedite a CMO analyst's understanding of the sociocultural dynamics in an operational environment where insurgency is likely or is already underway. The framework is firmly grounded in knowledge developed over decades of research in the social sciences. This grounding in the social sciences helps to focus the analyst's sensemaking efforts on those factors in the operational environment that are demonstrably relevant, thus helping to fit those analytical efforts into the tight operational planning cycle.

\section{ACKNOWLEDGMENTS}

The authors would like to thank all the members of the US Armed Services and recognize the valued support of our many collaborators and team members, including (alphabetically) Chandler Armstrong, Mark Armstrong, Ted Carmichael, Donald Conroy, Mirsad Hadzikadic, Eliza Johannes, Lisa Schirch, Andrea StrimlingYodsampa, William Tolone, James Walsh, Joseph Whitmeyer, and Dominick Wright.

Team members who contributed directly to the development of the analytical framework, i.e., concept for the foundational framework, methodology for the literature search, and development of the factor map with all its documentation are (alphabetically) Jennifer Burton, Kay McGuire, Natalie Myers, Duu Renn, Angela Rhodes, Isabel Scarborough, Keith Taylor, Neil Vander-Most, Judith Vendrzyk, and Wenshou Zhang. Without their tireless, dedicated, and innovative efforts, the analytical framework would not be as rich as it is.

The ideas articulated in this paper are the authors' alone and do not represent any official position of the US Army or Department of Defense. 


\section{REFERENCES}

Cutter, S., C. Burton, C. Emrich. 2010. "Disaster Resilience Indicators for Benchmarking Baseline Conditions." Journal of Homeland Security and Emergency Management $7(1)$.

Department of Defense, January 2012, Sustaining US Global Leadership: Priorities for 21 st Century Defense.

Goffman, E. 1974. Frame Analysis: An Essay on the Organization of Experience. London: Harper and Row.

Joint Staff. October 2011. Joint Publication 1-02, Department of Defense Dictionary of Military and Associated Terms (JP 1-02).

Joint Staff. January 2012. Joint Publication 2-01, Joint and National Intelligence Support to Military Operations (JP 2-01).

Joint Staff. June 2009. Joint Publication 2-01.3, Joint Intelligence Preparation of the Operational Environment (JP 2-01.3).

Joint Staff. November 2009. Joint Publication 3-27, Counterterrorism (JP 3-27).

Joint Staff. July 2008. Joint Publication 3-57, Civil-Military Operations (JP 3-57).

Kaste, R; E. Heilman, and R. Hoffman. 2007. Concept Map Value Propagation for Tactical Intelligence, Proceedings of the 12th International Command and Control Research and Technology Symposium.

Kitschelt, H.P. 1986. "Political Opportunity Structures and Political Protest: Anti-Nuclear Movements in Four Democracies." British Journal of Political Science 16(01):57-85.

McGinnis, M.D. 2011. "An Introduction to IAD and the Language of the Ostrom Workshop: A Simple Guide to a Complex Framework for the Analysis of Institutions and their Development." Version 1g, revised August 14, 2011. Accessed at http:// php.indiana.edu/ mcginnis/iad guide.pdf and Ostrom E. 2011. SES Framework: Initial Changes and Continuing Challenges. Draft.

Manwaring, M. G. and J. T. Fischel. 1992. "Insurgency and Counter-insurgency: Toward a New Analytical Approach.” Small Wars \& Insurgencies, 3(3):272-310.

Ostrom, E. 2011. "Background on the Institutional Analysis and Development Framework." Policy Studies Journal 39(1)1:7-27.

Piaget, J. 1952. The Origins of Intelligence in Children. New York: International University Press. 1954. The Construction of Reality in the Child. New York: Basic Books.

Rich, P.B. and I. Duyvesteyn. 2012. The Routledge Handbook of Insurgency and Counterinsurgency. New York: Routledge.

Schensul, S.L., J.J. Schensul, and M.D. LeCompte. 1999. Essential Ethnographic Methods. (Ethnographer's Toolkit Vol 2). Walnut Creek: Altamira Press.

Sieck, W.R., G. Klein, D.A. Peluso, J.L. Smith, and D. Harris-Thompson. 2007. FOCUS: A Model of Sensemaking. Technical Report 1200, United States Army Research Institute for the Behavioral and Social Sciences.

US Army Counterinsurgency Center. December 2011. Memo, "FM 3-24, Counterinsurgency, Revision Issue Paper \#1 - Definitions."

Zhang, W., N. Vander-Most, K. Taylor, I. Scarborough, and D. Renn. 2011. Pre-Intervention Analytical Framework. Draft Report. 


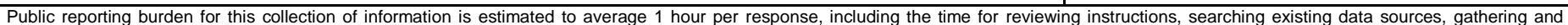

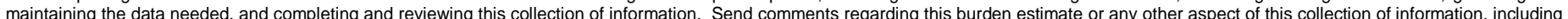

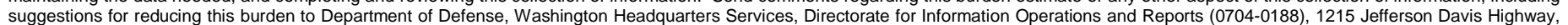

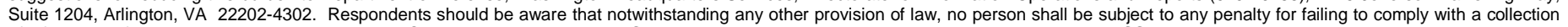
of information if it does not display a currently valid OMB control number. PLEASE DO NOT RETURN YOUR FORM TO THE ABOVE ADDRESS.

\begin{tabular}{l|l|} 
1. REPORT DATE (DD-MM-YYYY) & 2. REPORT TYPE
\end{tabular}

August 2012 Final

\section{TITLE AND SUBTITLE}

Towards a Pre-Intervention Analytical Methodology

5a. CONTRACT NUMBER

3. DATES COVERED (From - To)

5a. CONTRACT NUMBER

5b. GRANT NUMBER

5c. PROGRAM ELEMENT NUMBER

$622784 \mathrm{~T} 41$

6. AUTHOR(S)

Lucy A. Whalley, Timothy K. Perkins, David A. Krooks, Michael L. Hargrave, and

Chris C. Rewerts

5d. PROJECT NUMBER

P2335530

5e. TASK NUMBER

5f. WORK UNIT NUMBER

7. PERFORMING ORGANIZATION NAME(S) AND ADDRESS(ES)

US Army Engineer Research and Development Center

Construction Engineering Research Laboratory

P.O. Box 9005

Champaign, IL 61826-9005

8. PERFORMING ORGANIZATION REPORT NUMBER

ERDC/CERL MP-12-2

\section{SPONSORING I MONITORING AGENCY NAME(S) AND ADDRESS(ES)}

Headquarters, US Army Corps of Engineers

441 G Street NW

Washington, DC 20314-1000
10. SPONSOR/MONITOR'S ACRONYM(S) HQUSACE

11. SPONSOR/MONITOR'S REPORT NUMBER(S)

\section{DISTRIBUTION / AVAILABILITY STATEMENT}

Approved for public release; distribution is unlimited.

\section{SUPPLEMENTARY NOTES}

This text was originally presented as a paper at the "2nd International Conference on Cross-Cultural Decision Making: Focus 2012," July 2012, San Francisco, CA.

\section{ABSTRACT}

Few systematic methods are available to guide analysis of sociocultural dynamics for the planning of civil-military operations (CMO). Military practice provides limited guidance on how to address history and sociocultural context in planning. Each case is addressed as a unique situation, at a high cost in terms of time and effort. This text, first presented to the " 2 nd International Conference on Cross-Cultural Decision Making: Focus 2012," describes emerging results of a project entitled "Cultural Reasoning and Ethnographic Analysis for the Tactical Environment (CREATE)." A primary objective of the CREATE research is to develop a sociocultural analytical methodology to guide the sensemaking of analysts who support CMO planning.

The methodology centers on a formal analytical framework that organizes a wide variety of sociocultural factors that, according to the social science literature, directly and indirectly pertain to a specific problem space. Data sources, analytical methods, and tools are aligned with the framework to produce guidance on how to develop models of a particular situation. The focus of the framework is to provide insight from social science research into the drivers of instability in the partner nation to aid analysts in developing explanations for situations of interest to a combatant command.

\section{SUBJECT TERMS}

framework, sensemaking, sociocultural, civil-military operations (CMO), intelligence, analysis

\begin{tabular}{|l|c|c|c|l|l|}
\hline \multicolumn{2}{|l|}{ 16. SECURITY CLASSIFICATION OF: } & $\begin{array}{l}\text { 17. LIMITATION } \\
\text { OF ABSTRACT }\end{array}$ & $\begin{array}{l}\text { 18. NUMBER } \\
\text { OF PAGES }\end{array}$ & $\begin{array}{l}\text { 19a. NAME OF RESPONSIBLE } \\
\text { PERSON }\end{array}$ \\
\cline { 1 - 2 } $\begin{array}{c}\text { a. REPORT } \\
\text { Unclassified }\end{array}$ & $\begin{array}{c}\text { b. ABSTRACT } \\
\text { Unclassified }\end{array}$ & $\begin{array}{c}\text { c. THIS PAGE } \\
\text { Unclassified }\end{array}$ & 13 & $\begin{array}{l}\text { 19b. TELEPHONE NUMBER (include } \\
\text { area code) }\end{array}$ \\
\end{tabular}

